\title{
Differenz
}

Revista internacional de estudios heideggerianos y sus derivas contemporáneas

AÑO 5, NÚMERO 4: JULIO DE 2018. e-ISSN: 2386-4877 - DOI: 10.12795/Differenz.2018.i04.01

[pp. 11-28]

Recibido: 14/05/2018

Aceptado: 05/06/2018

\section{La dimensión temporal de la Befindlichkeit y la experiencia afectiva de la Zeitlichkeit en Sein und Zeit.}

\section{Befindlichkeit temporary dimension and Zeitlichkeit affective experience on Sein und Zeit.}

\author{
Roberto Ballester Corres \\ Universidad de Zaragoza
}

Resumen:

A través de la analítica existenciaria de Sein und Zeit, se busca establecer, mediante el análisis de la Befindlichkeit en tanto que modo esencial de apertura del Dasein, la cooriginariedad entre Verstehen y Befindlichkeit, así como prestar una especial atención a la angustia (Angst), y la posibilidad de pensar una experiencia afectiva -como apertura directa y preteórica- de la Zeitlichkeit, el sentido temporal del ser del Dasein. Para ello, será necesario analizar tanto la dimensión temporal de la Befindlichkeit, como el papel fundamental de la angustia en su hacer patente la muerte, el cuidado y, con ello, la resolución precursora del Dasein. Así, alcanzaremos a ver cómo la Zeitlichkeit sólo es abierta, en el proyecto propio de Sein und Zeit, bajo la forma de una experiencia fundamental de carácter afectivo, esto es, mediante la Grundbefindlichkeit de la angustia. 
Palabras Clave: Heidegger; temporalidad; afectividad; angustia; Ser y tiempo

\section{Abstract:}

Through Sein und Zeit existential analytic, we will try to establish, by the analysis of Befindlichkeit as an essential disclosedness way of Dasein, the equi-primordiality between Verstehen and Befindlichkeit, and a special attention to anxiety (Angst), the possibility of thinking an affective experience -as a direct and pre-theoretical disclosedness- about Zeitlichkeit. For that purpose, it will be necessary to analyze both the Befindlichkeit temporary dimension and the fundamental role of anxiety disclosing death, care and, with all that, resoluteness. Thus, we will get to see how Zeitlichkeit is only disclosed, on the project of Sein und Zeit, by the way of a fundamental and affective experience, rather, by the Grundbefindlichkeit of anxiety.

Keywords: Heidegger; temporality; affectivity; anxiety; Being and time

\section{Introducción}

En el presente artículo se pretende llevar a cabo un análisis del carácter temporal de la disposición afectiva (Befindlichkeit) en relación con la propia temporalidad (Zeitlichkeit) del Dasein, bajo la perspectiva de poder plantear, a través de la analítica existenciaria como desarrollo de la pregunta por el sentido del ser del Dasein en el contexto de Sein und Zeit, la posibilidad de una experiencia afectiva de la temporalidad. Para ello, se hará necesario exponer en qué medida, por un lado, la noción heideggeriana de Befindlichkeit no sólo hace referencia a un posible modo de estar en el mundo, sino primordialmente a un modo de apertura de carácter afectivo hacia todo ente por parte del Dasein, y, con ello, también a un modo de apertura respecto a la propia estructura existencial del ser-en-el-mundo (In-der-Welt-sein). En segundo lugar, habrá de verse en qué medida la Grundbefindlichkeit -que en el contexto de la producción heideggeriana que ha venido en denominarse "el proyecto de Sein und Zeit" es concretada en la angustia (Angst) - va a cumplir un papel fundamental, a través de su apertura a la muerte como perspectiva de la resolución de un ente al que, en su ser, le va su realizarse, en la resolución precursora en tanto que elemento articulador. Por último, partiendo del carácter extático-temporal del ser del Dasein y del análisis del propio carácter temporal de la Befindlicheit, concluiremos con el modo en que podemos entender la posibilidad de una experiencia afectiva, no sólo del tiempo de la cotidianidad, sino también de la propia temporalidad del Dasein cuyo acceso inmediato y preteórico devendrá, pues, a través de la Grundbefindlichkeit; experiencia que debe ser 
pensada, por lo tanto, como una experiencia fundamental (Grunderfahrung) ${ }^{1}$ que hace patente, necesariamente como "ser cada vez el mío" (Jemeinigkeit), el sentido temporal del ser del Dasein.

\section{La disposición afectiva como forma constitutiva de la aperturidad}

En el contexto de la analítica existencial, la Befindlichkeit es puesta en juego como una estructura co-originaria del ser-en, esto es, como una estructura configurante de la aperturidad por parte del Dasein al mundo y que es co-originaria respecto a la comprensión (Verstehen) y el habla (Rede) -en esa apertura del Dasein al mundo que, empero, es dada ya previamente en el Dasein bajo su articulación unitaria de "ser-en-el-mundo" (In-derWelt-sein)-. Así, como ya lo explicita Heidegger en los Prolegómenos para una historia del concepto de tiempo (curso del semestre de verano de 1925):

El carácter de descubrimiento que el encontrarse ${ }^{2}$ tiene concierne al estar siendo-en-el-mundo en cuanto tal, y en la vida cotidiana en concreto se encuentra uno siempre en aquello en lo que (se) para, ya que en todo lo que hacemos, en lo que (nos) paramos, decimos, nos "sentimos" de alguna manera (HEIDEGGER: 2006, p. 320).

Como se ve reflejado en esta cita, hemos de entender la disposición afectiva, pues, como un modo de acceso no sólo a lo ente, sino también a los otros y a uno mismo. Podemos decir, de forma sintética, que nos encontramos siempre afectivamente dispuestos en nuestro acceso a los entes del mundo, anímicamente determinados a través de este acceso originario de la disposición afectiva. Tal y como Heidegger refleja en $\S 29$ de SuZ, no consistiría el análisis de la afectividad en un estudio descriptivo del modo en que el Dasein experimenta los afectos (Affekten), bajo la consideración de los mismos como accidentes, como momentos siempre extrínsecos al modo de ser del Dasein, estados de afección psicosomáticos. Por el contrario, todo lo que comparece, todo lo que se fenomena, lo hace ya a partir de y en una disposición afectiva, sentido ontológico del temple de ánimo, la tonalidad afectiva o estado de acorde (Übereinstimmung), posibles

1 Klaus Held destaca, como pretendemos hacer nosotros, el carácter fundamental de la experiencia integrada en "Ios temples anímicos fundamentales" (Grundstimmungen) en tanto que experiencia del fundamento de ser del Dasein (HELD: 2015, p. 15).

2 Befindlichkeit, en traducción gaosiana; en caso de buscar un equivalente castellano nos decantaremos por la traducción de J. E. Rivera,"disposición afectiva". Resulta más que pertinente mencionar, no obstante, que el término "encontrarse" ha sido defendido también por especialistas a propósito de la afectividad en Heidegger como es el caso de Pilar Gilardi (GILARDI: 2013, pp. 157159, en nota a pie de página). 
variaciones descriptivas, todas ellas, de la Stimmung. Así, en este $\$ 29$, en un primer momento, bajo la pretensión de determinación de la facticidad -también- como síntesis pasiva de afectividad (en términos de fenomenología genética), Heidegger buscará estrechar el análisis de la Befindlichkeit al plantear, como uno de sus caracteres esenciales, el encontrarse afectivamente dispuesto al mundo en su estrecha relación inherente a la condición de arrojado, o "estado-de-yecto" [Geworfenheit]:

alcanzamos así el primer carácter ontológico esencial de la disposición afectiva: la disposición afectiva abre al Dasein en su condición de arrojado, y lo hace inmediata y regularmente en la forma de la aversión esquivadora (HEIDEGGER: 2009, p. 155).

Queremos destacar aquí que, asimismo, el temple de ánimo [Stimmung], como carácter óntico de la ontológica disposición afectiva, hace patente no otra cosa distinta al propio ser-en-el-mundo, ya que se presenta como un modo concreto de estar-siendo en el mundo, un modo concreto en el que el Dasein se muestra como una superación ontológica de la dualidad interioridad/exterioridad, debido a que el temple de ánimo, esta "tonalidad" en la que siempre nos encontramos, se vivencia como algo que nos afecta en nosotros mismos y al mismo tiempo como nuestra apertura al mundo: se nos abre un qué de lo óntico siempre desde un cómo afectivo (xolocotzl (ed.): 2014, pp. 12 y ss.; pp. 30 y ss.). Bajo esta noción de Stimmung como tono anímico, "Heidegger acentúa que este 'encontrarse' (Befindlichkeit) provocado por el orador no es un teñido subjetivo de las palabras proferidas, sino que más bien abre lo oído como tal" (REDONDO SÁNCHEZ: 2005, p. 46), que no es sino señalar que, en la relación intencional entre el Dasein y su circunmundo -relación que, por otro lado, no es sino lo mismo que enunciar Dasein, ese ser el Ahí en el que ya siempre está éste afectivamente-, no existe un afuera del tono. El Ahí abierto por el Dasein es siempre un Ahí afectivo y, por tanto, la Befindlichkeit debe pensarse como el "originario abrir de los estados de ánimo, en los cuales el Dasein queda puesto ante su ser en cuanto Ahi"' (HEIDEGGER: 2009, p. 154).

Así, obtenemos que el segundo carácter de la Befindlichkeit, en términos generales, es expresado por Heidegger en tanto que: "el estado de ánimo [Stimmung] ya ha abierto siempre el estar-en-el-mundo en su totalidad, y hace posible por primera vez un dirigirse hacia" (HEIDEGGER: 2009, p. 156). Este "hacer posible el dirigirse hacia" constata, pues, en qué medida podemos entender esta estructura ontológica de la disposición afectiva como conditio sine qua non para un acceso originario, preteórico, prediscursivo -en este primer momento-al ser del Dasein como ser-en-el-mundo. Tal y como señala Pilar Gilardi, a través de los estados de ánimo la existencia se revela como aquello que me ha sido 
confiado, a través de ellos se hacen patentes los caracteres que anteriormente hemos señalado del Dasein:

El tener que ser (Zu-sein) y el ser de este ente como cada vez mío (Jemeinigkeit). Los estados de ánimo revelan la existencia como aquello de lo que me tengo que hacer cargo, revelan el carácter ejecutante, dinámico de la existencia y el hecho de que ésta se juega siempre en primera persona (GILARDI: 2013, p. 132).

O, expresado por el propio Heidegger, ya en los primeros pasos del §29 de Sein und Zeit,

en el temple de ánimo, el Dasein ya está siempre afectivamente abierto como aquel ente al que la existencia [Dasein] le ha sido confiada en su ser, un ser que él tiene que ser existiendo (HEIDEGGER: 2009, p. 154).

En el tercer carácter esencial de la Befindlichkeit, esa apertura afectiva de la totalidad de lo que comparece experimenta un ejercicio de retorno, abriendo para el Dasein su propio ser como agente a la vez activo (en esta peculiar estructura intencional de la afectividad) que templa afectivamente lo compareciente, pero también pasivo, receptor, sufriente de la Stimmung que abre para el Dasein su propio afectarse, involucrando, al mismo tiempo, un determinado conocimiento de sí que va más allá de un conocimiento autorreflexivo del sí mismo y articulándose como la posibilidad de "estar-concernido" y de "estar-consignado" por los entes del mundo, haciendo posible la ocupación (Besorgen); puesto que, en este estar abierto afectivamente (Stimmungsmässig) por parte del Dasein, el posible dirigirse hacia los entes intramundanos debe pensarse, en primer lugar, bajo la forma del ser afectado (Betroffenwerdens) o el ser herido (angegangen werden) que hacen posible una primera apertura de mundo (Weltoffenheit) en la que lo intramundano se nos aparece ya de entrada como "amenazador", esto es, susceptible de afectar, herir. Ello provoca que el Dasein mismo, por tanto, sea abierto como ser afectado y herido -posibilitando la disposición afectiva, también, el ocuparse mismo de los entes intramundanos a los que se hace frente siempre desde este estar concernido afectivamente por ellos. Resulta cabal, por tanto, a propósito de este triple carácter de la Befindlichkeit, que el miedo (Furcht) se muestre, en la analítica existenciaria, como Stimmung paradigmática, pues es a través de ella como se muestra el carácter encubridor propio de la facticidad intrínseca al Dasein en su arrojamiento (Geworfenheit), suponiendo asimismo un punto de partida para la caída (Verfallen) a partir de la estrecha relación entre miedo y desviación esquivadora, puesto que, como bien señala el propio Heiddeger, "por lo regular, el Dasein esquiva, de un modo óntico-existentivo, el ser que ha sido abierto en el estado de ánimo (Stimmung)" (HEIDEGGER: 2009, p. 154). Sin embargo, como vamos a pretender apuntar en lo que sigue, 
esta primera consideración preliminar de la Befindlichkeit como estructura en estrecha vinculación con la facticidad puede ser superada por una visión más amplia bajo la cual se piense la Befindlichkeit como modo de aperturidad originario cuya estrecha vinculación con la Geworfenheit y la facticidad marcan, a nuestro parecer, un sentido privativo respecto a la comprensión -en tanto que de-limitador de la misma-, por lo que puede pensarse no necesariamente como desviación de la propiedad del tener-que-ser (Zu-sein) del Dasein -ello no sería propio de la facticidad, como sabemos, sino de la caída en el Uno (das Man)-, sino como orientación, a partir de una experiencia fundamental afectiva hacia el ser del Dasein.

Se hace preciso abordar, por tanto, en qué medida consideramos la disposición afectiva como un elemento fundamental para la constitución del ser del Dasein como cuidado (Sorge). Para ello, cabe reflexionar sobre la co-originariedad entre disposición afectiva y comprensión (Verstehen), existenciario que, como sabemos, abre para el Dasein las posibilidades abiertas y abre la existencialidad del Dasein en tanto que proyecto (Entwurf). Dicha co-originariedad implica no sólo una nivelación jerárquica entre estructuras, sino fundamentalmente una correlación entre ambas, una interdependencia por la cual la facticidad abierta por medio de la disposición afectiva -que eso que se descubre en todo temple sea el hecho de estar siendo- no hace sino patentizar que toda proyección de posibilidades se inserta siempre en el contexto de una situación en la que nos encontramos arrojados, una situación afectivamente determinada. Podemos afirmar, por tanto, que la comprensión habrá de ser siempre un comprender afectivamente templado, por cuanto siempre nos encontramos afectivamente dispuestos a unas determinadas posibilidades, demostrando, gracias a lo cual, que no sólo lo que comparece como ente, ni sólo la totalidad de nuestra facticidad, está marcado por un temple de ánimo, sino que también habrá de estarlo la posibilidad misma de nuestra realización, el desarrollo de nuestra resolución. Como señala Xolocotzi:

La propuesta de Heidegger en torno a la comprensión afectiva que es el Dasein no consiste meramente en ver la comprensión como algo determinado o determinante y la afectividad como su contraparte, sino que la correspondencia entre comprensión y afectividad es de hecho indeterminada por el carácter ontológico constitutivo del ente que conforman: el Dasein (xolocotzı: 2007, p. 204).

De esta indeterminación en la correspondencia entre ambos existenciarios podemos colegir, pues, que su diferenciación y articulación dual no es sino fruto del análisis del modo de ser el Dasein en su Ahí y no una diferencia dada en la experiencia fenomenológica por la que el Dasein se encuentra abierto al mundo ocupándose de él y de sí mismo. 


\section{La angustia como condición de la Sorge y de la resolución precursora: apertura angustiada del poder-ser-en-el-mundo y de la muerte como poder-ser entero}

Sólo mediante la angustia podrá entenderse cómo a través de la Befindlichkeit, el Dasein puede acceder, justamente, al sentido de su totalidad unitaria, a su resolución precursora como determinación auténtica del cuidado. En tanto que Grundbefindlichkeit, disposición afectiva fundamental, la angustia abre afectivamente al Dasein ante su poder-ser más propio $^{3}$, determinando angustiosamente ese estado de resuelto marcado por una apropiación auténtica del estar-vuelto-hacia-la-muerte constitutivo de la existencialidad del Dasein. Ante la cual, empero, no nos encontramos en una relación cotidiana con nuestro propio poder-ser. Va a ser en la significatividad media, cotidiana e impropia -porque desde ella no nos pensamos desde nuestro poder-ser más propio sino que nos asimilamos como entes acabados- donde irrumpa la angustia, poniéndonos, de golpe, sin previo aviso, ante nuestro poder-ser más propio, ante el ineludible tener-que-ser bajo la perspectiva de la muerte.

La angustia cumple, al mismo tiempo, la función metodológica de poner al Dasein ante su totalidad unitaria más allá de un mero ensamblaje de sus elementos constitutivos. Para alcanzar dicha unidad, pues, en palabras de Pablo Redondo: "se hace necesaria una experiencia existencial que abra fidedigna y genuinamente al Dasein en su ser" (REDONDO SÁNCHEZ: 2005, p. 109), que no es, pues, sino esta experiencia angustiada que, por un lado, sitúa al Dasein ante la nada -"la angustia revela la nada" (HEIDEGGER: 2003, p. 27)-, nada como ausencia de todo ente, no para arrojarnos a un vacío desasosegante, sino que "sólo en la clara noche de la nada de la angustia surge por fin la originaria apertura de lo ente como tal" (HeidegGeR: 2003, p. 31); asimismo, más apegados al carácter de resuelto de la muerte, por otro lado, la angustia se abre ante esa nada como final, como acabamiento de un determinado trayecto existencial. La angustia nos aísla del mundo entorno, nos des-ocupa y nos des-solicita; la angustia nos sitúa en la ausencia de lo ente, en un angustiarse de carácter indeterminado, del que no podemos dar cuenta desde una ocupación con los entes. Es la angustia misma la que nos "desasosiega" al abrirnos de manera inmediata a nuestro ser más propio, nuestro ser-en-el-mundo como aquello de lo que tengo que cuidarme, ante el hecho de ser: "un anticiparse-a-sí-estando-ya-en-(el-

3 "La angustia existencial también puede vivirse como singularidad abierta a otro poder-ser. Por eso la angustia es una voz, una interpelación, que nos pone en contacto con lo extraño, con el peligro, pero, recordando la frase de Hölderlin evocada por Heidegger, se trata de un peligro en el que crece también lo que salva, porque posibilita la apertura de una singularidad que nos revela el poder-ser propio, nuestro ser-posible" (RODRíGUEZ SUÁREZ: 2018, pp. 155-156). 
mundo) en-medio-de (el ente que comparece dentro del mundo)", estructura formal del ser del Dasein como cuidado.

A su vez, encontramos que la angustia, si abre angustiadamente al Dasein ante su ser como cuidado, es porque ella misma presenta una estructura intencional en la que se presentan afectivamente cada uno de los aspectos fundamentales del cuidado (facticidad, existencialidad, caída) manifestados en la disposición afectiva, la comprensión y el habla. Así, dice Heidegger en el importante $§ 41$ que:

El angustiarse, en cuanto disposición afectiva, es una manera de estar-enel-mundo; el ante-qué de la angustia es el estar-en-el-mundo en condición de arrojado; aquello por lo que la angustia se angustia es el poder-estaren-el-mundo. Por consiguiente, el fenómeno de la angustia tomado en su totalidad muestra al Dasein como un estar-en-el-mundo fácticamente existente (HEIDEGGER: 2009, p. 209).

Si atendemos a lo expuesto, la angustia no angustia por abrirnos el sentido de nuestro ser en tanto que unidad estructural entre existencialidad, facticidad y caída. Dichos elementos estructurales sólo se vuelven patentes a partir del análisis existencial elaborado por Heidegger. Sin embargo, en la angustia se nos revela la angustiosa estructura del cuidado por cuanto en ésta se nos abre el irnos nuestro ser más propio estando en un mundo determinado y en medio de un determinado trato con los entes que, sin embargo, es necesariamente puesto en suspensión en la angustia -a pesar de no ser objeto de nuestro análisis, cabe pensar el papel de la angustia como el elemento metodológico fundamental que hace salir al Dasein de su actitud media, ocupada, hermenéuticamente situada en el Ahí, ocupando la función metodológica de la dupla epojé/reducción transcendental de la fenomenología husserliana. En la angustia experimentamos la "inhospitalidad" de nuestro ser más propio. El ante-qué (Wovor) de la angustia, es decir, aquello que provoca nuestra angustia, no es en ningún caso un ente cualquiera temible bajo la característica de lo amenazante, sino que lo angustiante se nos presenta como nuestro propio estar-en-elmundo en cuanto tal. El hecho de que huyamos de nosotros mismos, de que nos demos la espalda, se funda en que nosotros mismos, entendiendo por tal nuestro propio consistir en un proyecto arrojado, en ser cuidado de sí, somos lo angustiante y lo angustiado a una vez. Así, en última instancia, aquello que nos angustia y aquello de lo que nos preocupamos al angustiarnos coincide estrechamente como nuestro propio poder-ser-en-el-mundo:

Con el "por" del angustiarse la angustia abre, pues, al Dasein como ser posible, vale decir, como aquello que él puede ser únicamente desde sí mismo [...]. La angustia revela en el Dasein el estar vuelto hacia el más 
propio poder-ser, es decir, revela su ser libre para la libertad de escogerse y tomarse a sí mismo entre las manos (HEIDEGGER: 2009, p. 206).

Así pues, si la angustia es comprendida aquí como Grundbefindlichkeit no es sino porque ésta supone un modo de apertura privilegiado, pues la angustia, en esa experiencia de la nada, y ese desasosiego debido a la apertura angustiada a nuestro más propio poder-ser, nos saca de la caída y nos sitúa ante el discernimiento de la propiedad e impropiedad de nuestro poder-ser. Vemos, pues, que la angustia juega un papel determinante de nuestro ser como cuidado siempre por mor de una determinada orientación, de una determinada posibilidad de propiedad abierta justamente en la angustia -abierta en aquello por lo que la angustia se angustia. Vemos, pues, que la angustia hace experimentar al Dasein que éste es un ente abierto y sometido a su realización bajo la posibilidad de la propiedad o la impropiedad y que va a marcar la dirección del poder-ser. Esta mostración por parte de la angustia no es simplemente un dejar-verse al Dasein en su "poder-ser" bajo la estructura formal del cuidado, sino que, como hemos visto, la angustia saca al Dasein de su estar-encasa y lo sitúa frente a su poder-ser más propio. Esto es debido a que la angustia, de algún modo, procura al Dasein anticipadamente una resolución en propiedad, un realizarse de forma auténtica. No obstante, la resolución precursora sólo es posible a través de una determinada relación con la muerte que determina al Dasein como un ser-parala-muerte. Este estar-vuelto-hacia-la muerte supone una anticipación constante. Dicha anticipación, al menos en su modalidad auténtica, en propiedad, disruptiva respecto del estado de caída, no se da sino mediante la angustia, puesto que "la muerte se revela así como la posibilidad más propia, irrespectiva e insuperable" y la angustia no es sino “angustia 'ante' el más propio, irrespectivo e insuperable poder-ser" (HEIDEGGER: 2009, p.267), determinando así el por-qué de la angustia, el motivo del angustiarse, aquello angustiante, como el poder-ser más radical del Dasein, esto es, la muerte.

Morir, la muerte propia, es, de acuerdo al §49, existencialmente el término reservado para "la manera de ser en la que el Dasein está vuelto hacia su muerte" (HEIDEGGER: 2009, p. 264), una muerte cuyo análisis existencial nos lo revela, por tanto, como elemento subordinado a la constitución fundamental del Dasein, esto es, subordinado a la estructura del cuidado y a la posterior constitución del poder estar-entero del Dasein. La muerte no es, por tanto, un factum brutum, sino eminentemente una posibilidad ante la que el Dasein está siempre anticipándose angustiadamente. Como señala François Dastur:

esta posibilidad que es la muerte ya no es, pues, una posibilidad entre otras, sino que resulta ser la posibilidad más propia a la vez que la posibilidad no superable y no relativa del Dasein (...) ésta [la muerte] no es el objeto de 
un saber "teórico", sino que se desvela originariamente y de forma más apremiante en la angustia (DASTUR: 2008, p. 170).

En la medida en que el Dasein es siempre su todavía-no, incapaz de experimentar su acabamiento, la muerte propia no puede sino darse como elemento constitutivo del propio proyecto, de la anticipación a su ser propio. En la medida en que el Dasein se comprende afectivamente como proyecto templado, la muerte deberá pertenecer como elemento fundamental a esa anticipación-de-sí-estando-ya-en-el-mundo propia del cuidado. La muerte habrá de ser, pues, una posibilidad experimentada afectivamente que, en tanto que posibilidad última, no puede abrirse afectivamente sino a través de la angustia.

Vemos pues que la muerte, en tanto que posibilidad inminente, posibilidad con la que el Dasein se encuentra siempre relacionado bajo la disposición fundamental de la angustia, determina propiamente la dirección de la anticipación-a-sí, del poder-ser propio. Dicho de otra manera: sólo bajo la perspectiva angustiada de la posibilidad extrema de la muerte puede el Dasein proyectarse en el modo de ser auténtico, ya que el Dasein se encuentra vuelto-hacia-la-muerte cuando se encuentra abierto -preteórica, afectivamente, por medio de la angustia- ante su totalidad estructural, su ser como cuidado, en tanto que articulado a través de la muerte como un arrojado (facticidad) estar-vuelto-hacia-sumuerte (existencialidad) huyendo de ella (estar-caído).

\section{La Grundbefindlichkeit como experiencia afectiva de la Zeitlichkeit: interrelación entre la estructura temporal de la afectividad y la estructura temporal del Dasein}

Si asumimos la afirmación de Pablo Redondo según la cual "se hace necesaria una experiencia existencial que abra fidedigna y genuinamente al Dasein en su ser" (REDONDo SÁNCHEZ: 2005, p. 109) y otorgamos, por lo visto hasta ahora, a la angustia dicha función; y si, como pretende Heidegger, entendemos que ese poder-estar-entero alcanza su posibilidad más extrema e irrenunciable en la muerte -que es siempre un estar-vueltohacia-el-fin, bien sea cotidiana o auténticamente- y si entendemos que la angustia es en última instancia angustia ante la muerte, apertura afectiva de la nada y apertura afectiva de nuestro poder-ser ontológico dado como resolución; es preciso entender el papel que juega la disposición afectiva y, de manera esencial, la disposición afectiva fundamental de la angustia, en el carácter extático y puramente tempóreo del Dasein, que nos llevará a afirmar que la disposición afectiva -en términos generales, pero sobre todo una Grundbefindlichkeit que suponga un acceso originario al sentido más propio del ser del Dasein como cuidado, la resolución precursora, y que, a su vez, suponga una 
condición necesaria para la resolución- es el único modo en que el Dasein puede tomar acceso auténtico, no intelectivo ni analítico, de su propia temporalidad. La temporalidad constitutiva del Dasein, la Zeitlichkeit no será experimentada, como vamos a tratar de establecer, sino como experiencia afectiva en general y como experiencia angustiada en particular. Sólo así podrá entenderse en qué medida, por tanto, la angustia es constitutiva de nuestra propio ser (xolocotzı (ed.): 2014, p. 106).

Nos vemos obligados, por falta de espacio, a renunciar a una tematización en extenso del acceso cotidiano, una comprensión vulgar del tiempo que, sin embargo, también deberá pensarse como experiencia templada -pues no hay acceso a lo ente que, como ya hemos visto, no esté atravesado por una determinada pátina afectiva-, que debemos entender, por un lado, como un tiempo de magnitudes calculables, de un tiempo-ahora, que coincidirá con una constitución científico-cosmológica de un tiempo de la naturaleza y, por otro lado, como un tiempo óntico, la intratemporalidad de los entes intramundanos, próxima, en última instancia, a la conciencia interna del tiempo de los objetos percibidos en la fenomenología de Husserl. Centrémonos, por tanto, en esa otra temporalidad de la que no tenemos acceso cotidianamente, pero que es, empero, condición de esa otra comprensión vulgar del tiempo y sentido, a su vez, del ser del Dasein como cuidado: el tiempo que soy yo mismo, el tiempo que es siendo el Dasein. Así, la temporalidad, como tiempo originario estará en estrecha conexión con los momentos estructurales vistos en el cuidado -el cuidado va a configurarse ahora como expresión de este modo de ser del Dasein. Sólo puede entenderse, a partir de la determinación de la temporalidad como horizonte de comprensión del cuidado, la primacía de la anticipación-a-sí y el papel de la muerte como expresión de la finitud de la temporalidad (Zeitlichkeit), una temporalidad que, por otro lado, debe pensarse como "el sentido propiamente temporal de la existencia en tanto que modo de ser exclusivamente humano" (DASTUR: 2006, p. 12).

Así pues, ¿cómo determinamos dicha Zeitlichekeit? Si no se trata de un tiempo del ahora, de un tiempo del presente, si no es, siquiera, la conciencia de una secuencia en duración que determine la unidad del objeto intencional, ¿ cómo se articula la temporalidad ontológica, propia del ser del Dasein? Tanto en Sein und Zeit como en Los problemas fundamentales de la fenomenología (curso de Marburgo de 1927), Heidegger describe la estructura de la temporalidad como estructura extático-horizontal, consistente en que:

Futuro, haber-sido, presente, muestran los caracteres fenoménicos del "hacia-sí" (Auf-sich-zu), del "de-vuelta-a" (Zurück auf) y del "hacercomparecer-algo" (Begegnenlassen von). Los fenómenos del "hacia...", del "a...", del "en medio de..." manifiestan la temporeidad [Zeitlichkeit] como lo

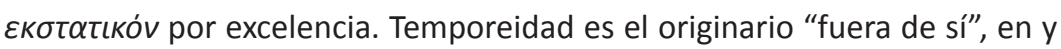


por sí mismo. Por eso, a los fenómenos de futuro, haber-sido y presente ya caracterizados los llamados éxtasis de la temporeidad. La temporeidad no es primero un ente que, luego, sale de sí, sino que su esencia es la unidad de los éxtasis (HEIDEGGER: 2009, p. 344).

Se da la temporalidad, propiamente, como un encontrarse "en dirección a" un determinado horizonte temporal, un determinado horizonte del éxtasis que demarca su dimensión extático-horizontal. Así, en la medida en que entendemos la temporalidad como unidad originaria de la estructura de cuidado, esta direccionalidad de la temporalidad no debe ser entendida sino como el mismo movimiento intrínseco de anticipación por el cual "el futuro tiene una primacía en la unidad extática de la temporalidad originaria y propia" (HEIDEGGER: 2009, ídem). Si debemos entender la resolución precursora como el estarvuelto-hacia el más propio, extremo e inminente poder-ser, verbigracia, como estar vuelto hacia la muerte (forma propia de la totalidad del cuidado), ésta se revela posible en tanto que perteneciente al éxtasis originario y fundamental del futuro, que tendrá su fenómeno originario en el porvenir (Zukunft) en tanto que advenir hacia sí mismo en su más propio poder-ser por parte del Dasein. En la medida en que está siempre adelantándose en forma propia hacia su muerte, la tensión extática de la temporalidad tendrá su primacía en el futuro como porvenir de sí mismo.

Por su parte, tal y como se veía también en la estructura del cuidado, la resolución precursora adviene futuribilidad en la medida en que se hace cargo de su estar arrojado. Por tanto, el éxtasis del pasado se fenomena originariamente, a partir de la intrínseca relación con el porvenir, como "lo que ya siempre era", como su haber-sido (Gewesenheit). En tanto que el Dasein es venidero a sí, siempre ha sido, siempre está siendo su sido. En una comprensión vulgar del tiempo en la que el Dasein se entiende en tanto que subsistente, en tanto que presencia, el pasado permanece como aquello que ya no es. Sin embargo, en la temporalidad propia del Dasein en la que el Dasein está siempre adviniendo, lo hace retornando hacia lo sido que ocuparía el lugar habitual del es. Puede decirse, por tanto, que en toda anticipación propia, en todo advenir, la actualidad es pasada y es pasada en la medida en que recoge lo que siempre ya ha sido a partir del horizonte extático del porvenir.

Así pues, en la medida en que se manifiesta la temporalidad extática como tiempo no lineal ni presentista, el espacio que queda al éxtasis de presente será el de la apertura a los entes intramundanos, el estar en medio de los entes con los que nos ocupamos en una situación determinada y, por tanto, se fenomena en la presentación (Gegenwärtigen), en el hacer presencia, de los entes del mundo circundante, $y$, a su vez, originariamente, si asumimos este tiempo como el de la resolución precursora, el presente consiste en 
el instante (Augenblick), que lejos de ser un momento puntual, un ahora, se encuentra incluido, aglutinado, por el futuro y el haber-sido, siendo pues éste la situación abierta misma que anticipa siendo sido entre los entes del mundo. Se perfila, por tanto, que, si hemos de considerar la temporalidad como un fenómeno unitario, ésta se muestra entonces "como un futuro que está siendo sido y que presenta" (HEIDEGGER: 2009, p. 341).

Ésta es, pues, la unidad de la temporalidad y éste el sentido temporal del cuidado. En la medida en que entendemos la estructura del cuidado como "un anticiparse-a-sí-estandoya-en-(el-mundo) en-medio-de (el ente que comparece dentro del mundo)", vemos la unidad de esta misma estructura, ahora develada en su carácter temporal, como la unidad de los éxtasis de la temporalidad que ponen de relieve que sólo a partir de la temporalidad es posible dicha unidad del cuidado. Sólo comprendiendo que "la unidad originaria de la estructura del cuidado es la temporeidad" (HEIDEGGER: 2009, p. 342) cobrará sentido la pregunta abierta llevada a cabo por Heidegger en su conferencia de 1924, El concepto de tiempo, según la cual: "La cuestión de ¿qué es el tiempo? se ha convertido en la pregunta: ¿Quién es el tiempo?” (HEIDEGGER: 1999, p. 60), por cuanto, por un lado, en la Zeitlichkeit se juega el sentido mismo de la unidad de la Sorge, ser del Dasein; pero también, por otro lado, por cuanto la Zeitlichkeit, en tanto que temporalidad propia de la existencia humana, no puede interpretarse sino bajo el horizonte de una autoafección (ESCUDERO PÉREZ: 2014, pp. 97-99): un venir a sí mismo en la constatación del cada vez mío (Jemeinigkeit) del cuidado, que podemos traducir como el verse afectado por ese mismo sentido del ser del Dasein en la medida en que el Dasein se sitúa, por medio de la angustia, ante su poder-sermás-propio. A propósito de la afectación por parte del tiempo -que entronca claramente, a nuestro modo de ver, con el segundo de los caracteres previamente mencionados de la estructura de la Befindlichkeit-, que se sugiere, se apunta, pero no se concreta en esta conferencia. A este respecto, J. Ordóñez-García y K. Rüdinger señalan:

¿qué es aquello que me afecta de tal modo que me impele a interrogarme por el tiempo? Este se nos da, al pronto, y según lo preguntado, a resultas de una afección: el tiempo me afecta (ORDóÑEZ-GARCíA \& RÜDINGER: 2014, p. 158).

El sentido que esta apelación al propio Dasein por parte de su propia estructura temporal tiene deberá comprenderse a través de la vinculación entre Zeitlichkeit, Sorge, Angst y Sein zum Tode, siempre bajo la perspectiva de la resolución precursora. En esta estrecha relación se juega, propiamente, el es geht dem Dasein um sein eigenes Sein -el irle al Dasein su ser propio- (HEIDEGGER: 2006, p. 368), esto es, el carácter de propiedad o impropiedad que sólo es posibilitado por aquella realización que es abierta a partir de la angustia, en su papel constitutivo de dicha resolución (xolocotzı (ed.): 2014, p. 106): 
"la entrega del Dasein a sí mismo se muestra originaria y concretamente en la angustia" (HEIDEGGER: 2009, p. 210).

Por tanto, encontramos que si la temporalidad otorga el sentido al cuidado, y la resolución precursora se comprende como el cuidado propio en el que se está vueltohacia la muerte para tomar las posibilidades propias, debe colegirse que la temporalidad se temporiza originariamente desde el advenir de la muerte, desde la muerte como horizonte extático abierto en el porvenir y desde el cual "advengo siendo sido". En la repetición del haber-sido, tal y como se muestra en el porvenir finito, adquiere sentido mi muerte como fenómeno de mi intrínseca temporalidad. Y si, como resulta evidente, tomamos la muerte como el más extremo e irrenunciable haber-sido anticipado por el porvenir, observamos que, si bien el fenómeno fundamental del tiempo es el futuro, éste se da en la medida en que se orienta hacia el más propio y extremo haber-sido. Desde esta perspectiva, creemos poder plantear, desde la lectura precedente de la unidad de los éxtasis de la temporalidad y el papel de la muerte en ella, así como del carácter propiamente temporal de la propia muerte como haber-sido, la experiencia fundamental del tiempo que se halla en la disposición afectiva de la angustia, planteando así tal experiencia como una expresión auténtica del tiempo originario sin la distorsión de la comprensión vulgar del tiempo .

En el §68, pues, nos encontramos con que:

es el éxtasis del haber sido el que hace posible el encuentro consigo mismo en la forma del encontrar-se afectivo [...]. La disposición afectiva se temporiza primariamente en el haber-sido (HEIDEGGER: 2009, p. 355).

La angustia, definida como disposición afectiva fundamental, es asimismo entendida como aquel temple de ánimo capaz de encaminar al Dasein a su resolución precursora por la apertura angustiada ante la posibilidad más propia y extrema de la muerte. Con ello, tal y como se plantea en la analítica existenciaria, es (con ello) la apertura a nuestro más propio estar arrojado. En la medida en que coinciden el "ante-qué" y el "por-qué" en el Dasein como poder-ser abierto a la nihilidad de la muerte y ante su poder-ser más propio, Heidegger se pregunta: “¿no queda entonces constituida la angustia por un futuro? [y responderá] Ciertamente, pero no por el futuro impropio del estar a la espera" (HEIDEGGER: 2009, p. 358). Sin embargo, Heidegger mantiene la primacía del "haber-sido" al considerar que:

La angustia lleva de vuelta hacia la condición de arrojado como posibilidad repetible. Y de esta manera ella revela también la posibilidad de un modo propio de poder-ser, que en la repetición debe retornar, como poder-ser 
venidero, hacia el Ahí arrojado. Llevar ante la posibilidad de ser repetido es el modo extático específico del haber-sido que constituye la disposición afectiva de la angustia (HEIDEGGER: 2009, ídem).

Heidegger insiste, por tanto, en que la angustia se funda originariamente en el "habersido", en la medida en que la repetición, propia del éxtasis del haber-sido, pone en el horizonte de la posibilidad un haber-sido resuelto. No obstante, se repite un haber-sido, como veíamos antes, en la medida en que el futuro hace posible ese advenir de nuevo del haber-sido, que no se re-actualiza sin más -eso sería propio del tiempo presentista impropio-, sino que se repite por el hecho mismo de ser venidero, articulándose el sentido temporal primario de la angustia en el haber-sido, pero no tomándolo a él como éxtasis predominante. El haber-sido es aquello que se repite y, por tanto, aquello por lo que se angustia la angustia desde el advenimiento anticipador primordial del éxtasis del porvenir que precisamente permite que el Dasein se angustie por su resolución:

En la temporeidad característica de la angustia, es decir, en el hecho de que ella se funda originariamente en el haber-sido y de que sólo a partir del haber-sido se temporizan en ella el futuro y el presente, se revela la posibilidad del poder que es propio del estado de ánimo (Stimmung) de la angustia [...]. Le da también la posibilidad de un poder-ser propio (HEIDEGGER, M: 2009, p. 359).

Así, en la medida en que la muerte determina la temporalidad como temporalidad finita, puede deducirse que es a partir del desvelamiento angustiado de nuestro fáctico poder-ser más extremo como el Dasein alcanza conciencia de su propia finitud, marcando el camino, así, hacia su estado de resuelto por el haber-sido repetido en la anticipación originaria del porvenir. De ello se colige que el ante-qué y el por-qué de la angustia son los dos momentos de esa repetición, por cuanto la angustia repite desde el porvenir en el "ante-qué" el haber-sido del "por-qué" de la angustia, repetición que se da en el instante de la afección, que marca su éxtasis presente originario. Por otro lado, se presenta la angustia, en su carácter disruptivo, en su desasimiento de la cotidianidad impropio, como aquella disposición afectiva que hace posible una salida abrupta de la comprensión vulgar del tiempo. Como señala Michel Haar: "la tonalité de l'angoisse (...) interrompt le tempsdu-monde comme Heimlichkeit absolue, comme continuité réglée de l'enchevêtrement d'activités" (HAAR: 1996, p. 76).

Así pues, si asumimos la estructura extático-horizontal de la Zeitlichkeit como la primacía de una futuración en el que se da el advenir de un haber-sido presentificado en el instante otorgado por la resolución, encontramos una coincidencia estructural con 
la temporalidad, en tanto que la angustia se revela como una estructura unitaria de sus éxtasis temporales como repetición (haber-sido) en el instante de la resolución precursora (porvenir). A la vez, en la medida en que no hay comprensión sin afección ni afectividad que no sea al mismo tiempo comprensora, no debe confundirse el éxtasis primario de la disposición afectiva con que ésta se encuentre sometida a ser la experiencia de un "habersido" afectivo y, por otro lado, la comprensión con un abrir las posibilidades en el porvenir.

\section{Conclusión}

Se constata, pues, que la experiencia afectiva de la temporalidad no es una representación templada de un sentido que le sobrepasa. La unidad extática de la temporalidad dependería de esa apertura de la angustia a su propia finitud para entender el movimiento de repetición en el porvenir de ese haber-sido irrenunciable como es la muerte. Quedaría mucho camino aún, sin embargo, para llegar a deducir de ello que en Heidegger la angustia funciona como conditio sine qua non de la temporalidad como sentido del ser del Dasein, pero se observa, empero, que la angustia sitúa al Dasein ante su propia temporalidad: la angustia abre la temporalidad. De ello entendemos, por tanto, que a partir de la disposición afectiva esa apertura tiene el sentido de una experiencia afectiva de la temporalidad, pero también, que no puede dársele la temporalidad al Dasein sino afectivamente, ya que, como hemos visto, el único modo de acceso inmediato, la única experiencia, de la temporalidad en su propiedad e integridad es a partir de la angustia misma, siendo sólo posible acceder de otra manera a una relación cotidiana e impropia con el tiempo, pues lo abierto en la angustia no es sino ese sentido temporal del cuidado como "anticipación de un haber-sido que se presentifica".

Dicha conclusión habrá de ser susceptible de ampliarse, en las obras posteriores, al aburrimiento ${ }^{4}$ en tanto que Grundbefindlichkeit ${ }^{5}$ e, incluso, da pie a concluir, como señalan Ordóñez-García y Rüdinger acertadamente, a nuestro parecer, que el tiempo (bien sea propio, bien sea impropio) no es captado experiencialmente sino como algo que se siente, como una experiencia afectiva por parte de diversos Stimmungen, pero cuya

4 Si bien prima aún la angustia como Grundbefindlichkeit en su apertura a la nada, ya en Was ist Metaphysik? (1929) es claramente introducido el temple anímico del aburrimiento, o tedio, en relación con el sobrecogimiento de un "todo" abierto por tal Stimmung (HEIDEGGER: 2003, pp. 2324).

5 Para Held, la Kehre sólo es pensable a partir de la atención a esta Grundbefindlichkeit: "De esta manera es de la 'escucha' de los temples fundamentales así comprendidos de donde la reflexión ontohistórica de Heidegger recibió su obligatoriedad y su disposición a la irrupción en la década que siguió a Ser y tiempo" (HELD: 2015, p. 16). 
temporalidad propia sólo se experiencia afectivamente como experiencia primaria de la muerte (ORDÓÑEZ-GARCíA \& RÜDINGER: 2014, pp. 158-161). Dicha experiencia afectiva de la Zeitlichkeit está también en la base, creemos, de una específica diferencia posterior entre indicación-del-tiempo (Zeit-Angabe) y donación-del-tiempo (Zeit-Gabe), presente en los Zollikoner Seminare (HEIDEGGER: 2013, p. 81), cuyo tiempo donado al Dasein de forma inmediata, antepredicativa y preteórica (por parte de la angustia, añadimos) no es otro que la Zeitlichkeit. Así, sería posible pensar, desde la perspectiva heideggeriana, un fructífero avance de carácter ontológico hacia la pretensión husserliana de determinar un tiempo vivido (Lebenszeit) que, en este caso, no depende del análisis de la conciencia inmanente del tiempo en el objeto intencional sino de una determinada experiencia afectiva capaz de hacer vivencia intencional de la constitución temporal del Dasein.

\section{Bibliografía}

ADRIÁN ESCUdERO, Jesús: Guía de lectura de Ser y tiempo, de Martin Heidegger, vol. I-II. Barcelona: Herder, 2016.

DASTUR, Françoise: Heidegger y la cuestión del tiempo. Buenos Aires: Del Signo, 2006 DASTUR, Françoise: La muerte: ensayo sobre la finitud. Barcelona: Herder, 2008.

ESCUDERO PÉREZ, Alejandro: “Del existir temporal: Heidegger y el problema del tiempo" en Ápeiron: estudios de filosofía 1, 2014, pp. 97-174.

GILARDI, Pilar: Heidegger: la pregunta por los estados de ánimo (1927-1930). México: Bonilla Artillas Editores, 2013.

HAAR, Michel: "Le moment, l'instant et le temps-du-monde" en couRTINE, Jean-François: Heidegger 1919-1929: de l'hermeneutique de la facticité à la métaphysique du Dasein. Paris: Libraire Philosophique J. Vrin, 1996, pp. 67-91.

HEIDEGGER, Martin: El concepto de tiempo, trad. de J. Adrián Escudero y R. Gabás. Madrid: Trotta, 1999.

HEIDEGGER, Martin: Los problemas fundamentales de la fenomenología, trad. de J.J. García Norro. Madrid: Trotta, 2000.

HEIDEGGER, Martin: Ser y tiempo, trad. de J. E. Rivera. Madrid: Trotta, 2009.

HEIDEGGER, Martin: ¿Qué es metafísica?, trad. de H. Cortes y A. Leyte. Madrid: Alianza, 2003. 
HEIDEGGER, Martin: Prolegómenos para una historia del concepto de tiempo, trad. esp. de J. Aspiunza. Madrid: Alianza, 2006.

HEIDEgGer, Martin: Seminarios de Zollikon, trad. de Á. Xolocotzi. México: Herder, 2013. HELD, Klaus: "Temple anímico fundamental y crítica a la cultura contemporánea en Heidegger" en Revista Co-herencia vol. 12, 23, 2015, pp. 13-40.

LEYTE, Arturo: Heidegger. Madrid: Alianza, 2005.

ORDÓÑEZ-GARCíA, José \& RÜDINGER, Kurt: “Heidegger y la noción de preciencia (Vorwissenschaft) como propedéutica existencial. (Parte 1: El afecto del tiempo)" en Estudios de filosofía 50, 2014, pp. 155-169.

REDONDO SÁNCHEZ, Pablo: Filosofar desde el temple de ánimo: la "experiencia fundamental" y la teoría del "encontrarse" en Heidegger. Salamanca: Ed. Universidad Salamanca, 2005. ROdríGUeZ GARcíA, Ramón: Hermenéutica y subjetividad. Madrid: Trotta, 1993.

RODRÍGUEZ GARCÍA, Ramón: Heidegger y la crisis de la época moderna: Madrid, Síntesis, 2010.

RODRígueZ GARCíA, Ramón (coord.): Ser y tiempo de Martin Heidegger: un comentario fenomenológico. Madrid: Tecnos, 2015.

RODRÍGUEZ SUÁREZ, Luisa Paz: "El sentido de la angustia en el mundo técnico" en Utopía y Praxis Latinoamericana: Revista internacional de filosofía y teoría social 80, 2018, pp. 145-158.

Xolocotzl, Ángel: Subjetividad radical y comprensión afectiva: el rompimiento de la representación en Rickert, Dilthey, Husserl y Heidegger. México: Plaza y Valdés, 2007. xolocotzl, Ángel (ed.): Studia Heideggeriana. 4, Afectividad. Buenos Aires: Teseo, 2014. 